\title{
Hair Removal by Using Laser Different
}

\author{
Dr. Hashim Fathi Yassin \\ University of Mosul, College of Science, Dept. of Physics
}

\begin{abstract}
The need for a rapid, famous method for hair removal has led to the development of various laser for hair removal. These include ruby, alexandrite, diode, and Nd:YAG lasers. This research discusses the basic principles of laser hair removal, examines theoretically the properties of specific laser systems, and focuses on patient selection and treatment protocols for the various systems designed to ensure safe and effective treatment.
\end{abstract}

Key Words: Hair removal, laser procedure, $694 \mathrm{~nm}$, ruby lase $755 \mathrm{~nm}$,Alexandrite1064nm and Nd;YAG laser.

\section{Introduction}

Over the years, numerous laser and light-based devices have been developed to effectively remove unwanted hair. These innovations have been based on applying principles of laser physics to selectively targeted hair follicles. As our understanding of hair biology has grown and laser technology has advanced, various different light-based sources have become increasingly effective and efficient in removing undesirable hair. This review will focus on the most popular laser devices commonly used today, which include the alexandrite, diode, and 1064 Nd:YAG lasers.

All human hair shows various stages of hair growth (1). The anagen or growth phase is variable in duration (up to six years) and leads to the catagen or regression phase, which is usually constant at around three weeks. The telogen or resting phase follows just prior to the resumption of the anagen phase and lasts approximately three months. At any given time, the majority of hair follicles $(80-85 \%)$ are in anagen and the remaining follicles are either in the catagen phase (2\%) or the telogen phase (10-15\%).(Figure 1).

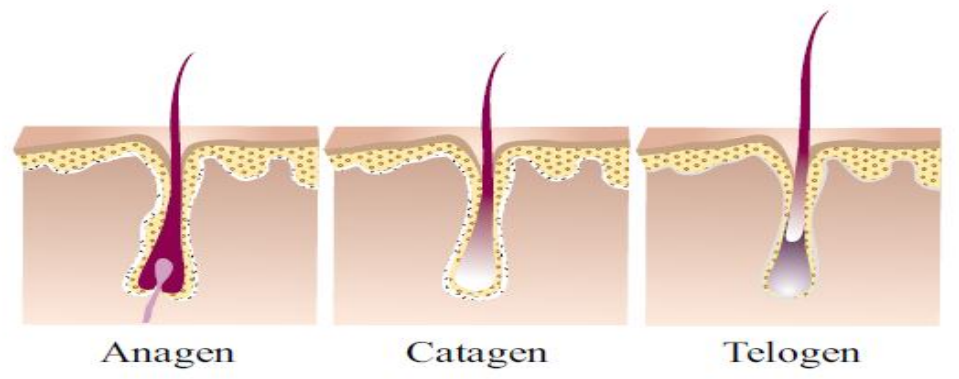

Figure 1 Hair growth cycle.

The anagen duration varies greatly depending on age, season, anatomic region, sex, hormonal levels, and certain genetic predisposition. For example, scalp hair are in the anagen cycle from 48-72 months, while thigh and leg hairs are in anagen from 1-6 months. It is these variations that lead to the tremendous disparity in hair cycles reported by various investigators (1-5). Long-term hair removal requires a laser or light source impact on one or more growth centers of hair. Anecdotal approaches have suggested that the pluripotent stem cells of the bulge, papilla, and hair matrix must be treated in the anagen cycle for effective hair removal [2]. If the damage is not permanent during this cycle, it has been suggested that follicles will move into the telogen stage as they fall out. Thus, all the follicles may become synchronized after the first laser treatment, providing the patient a temporary reduction of approximately three months. The hair follicle will then return to anagen based on the natural hair cycle.However, this time-honored theory of optimal anagen treatment times has been challenged by Dierickx et al., whose widely acceptedfindings suggest that anagen/telogen cycling does not have the significant impact on laser induced response as was earlier thought ( 7 ). In accordance with this view, mostclinicians have found that attempts to correlate hair removal efficacy with growth cyclesto be fruitless. Another view has emerged since a recent study by Orringer et al. examined the effects of laser hair removal on the immunohistochemical properties of hair follicles using both a1064 nm Nd:YAG laser and an $800 \mathrm{~nm}$ diode laser ( 8 ). After a single laser treatment, they found that the immunostaining properties of the follicle, including the bulge region, remained mostly unchanged.They concluded that laser hair removal may occur by a functional alteration of follicular stem cells, rather than the commonly viewed theory of light source- based hair destruction. Currently, there is no agreement on a definition for treatment-induced "permanent" hair loss.In addition, there are no studies evaluating the long- 
term durability of laser hair removal. permanence, defined as an absolute lack of hair in a treated area for the lifetime of the patient,may be an unrealistic goal. Most researchers agree with Dierickx et al., who have proposed todefine "permanent" hair loss as a significant reduction in the number of terminal hair after a giventreatment, that is stable for a period longer than the complete growth cycle of hair follicles at any given body site (6). If no hair regrows after this time period, it can be assumed that the growth centers have no capacity to recover from injury, and are not simply in telogen.

It is now accepted that almost any laser can induce at least a temporary hair loss. Flounces as low as 5 $\mathrm{J} / \mathrm{cm} 2$ can induce this effect, which tends to last 1-3 months. The mechanism of action appears to be an induction of catagen and telogen. Permanent hair reduction, occurring at higher flounces is seen in $80 \%$ of individuals, seen with a variety of light-based systems, and is flounce-dependent.

\section{How Does Laser Hair Removal Work?}

The laser puts out very short pulses of intensely bright light. This light penetrates into the skin and is absorbed by hairs that are brown or black. When absorbed, the light energy is converted into heat and the hair and the cells from where the hair is growing (hair follicle) are heated. The heating causes damage to the hair follicle almost all of the treated hair falls out within 1 to 2 weeks with traditional laser hair removal. After 6 weeks to 6 months there is gradual regrowth of some of the hair. There is usually less of it than before and often the hair is usually thinner and somewhat lighter in color.

\section{Selection Lasers For Hair Removal}

The most appropriate lasers are those with wavelengths between 700 and $1400 \mathrm{~nm}$, because this range offers the greatest absorption of melanin and the least interference with other pigments, such as hemoglobin.

The lasers most frequently used are:

\section{Ruby laser (694 nm)}

\section{Alexandrite laser $(755 \mathrm{~nm})$ \\ 3. Diode laser $(800 \mathrm{~nm})$ \\ 4. Nd:YAG laser $(1064 \mathrm{~nm})$}

\section{Ruby laser (694 nm):-}

The first introduced the concept of laser hair removal in 1996. With normal mode ruby laser system $(694 \mathrm{~nm})$, and fluences of 20 to $60 \mathrm{~J} / \mathrm{cm}^{2}$ were used. This wave length deeply penetrates into the dermis, where follicular melanin is by far the dominant chromophore(9).A variety of ruby laser systems have come and gone over the years. They were best used in light skinned individuals with dark hairs. This limited their use in many clinics and paved the way for other systems to emerge.

\section{Alexandrite laser $(755 \mathrm{~nm})$;-}

Alexandrite laser systems have longer wavelengths than their ruby laser counterparts (755 - $694 \mathrm{~nm}$ ). They have the ability to penetrate deeper than ruby lasers and are less absorbed by epidermal melanin; they have had greatstaying power in treating many skin types. In (10) showed that with a variable-pulsed alexandrite laser, hair reductions of $40 \%$ to $56 \%$ could be achieved at 6 months after a single treatment. In (11-12)performed work on the long-pulsed alexandrite lasers and showed similar efficacies with minimal adverse effects.

Last systems uses a3millisecond pulse duration, from8 to $18-\mathrm{mm}$ spot sizes, fluencies of 10 to $100 \mathrm{~J} / \mathrm{cm}^{2}$, and its own specially designedcryogen spray system for epidermal cooling, known as the dynamic cooling device.

\section{Diode laser $(800 \mathrm{~nm})$;-}

Diode lasers emit monochromatic laser light at a wavelength of $800 \mathrm{~nm}$ or $810 \mathrm{~nm}(13-15)$ which evaluated the effectiveness and safety of an $810 \mathrm{~nm}$ pulsed diode laserfor the permanent reduction of unwanted hair.With pulse widths that vary from 5 up to a newly introduced model, up

to 400 milliseconds, allowing darker skin types to be easily treated. The spot size is $12 \times 12 \mathrm{~mm}$, and it uses a fast repetition rate of $2 \mathrm{~Hz}$, as well as flounces between 10 and60 J/cm2.

In (21)found that systems to be equal in efficacy. A different group studied the effect of various spot sizes on hair removal efficacy with a long-pulsed diode laser and found that a larger spot size $(14 \mathrm{~mm})$ was superior to a smaller spot size $(8 \mathrm{~mm})$ (16). Finally long-pulsed diode laser safe and effective at removing hair in AfricanAmerican patients (17).

\section{Nd:YAG laser (1064 nm);-}

$\mathrm{Nd}$ :YAG lasers typically emit light with a wavelength of $1064 \mathrm{~nm}$, in the infrared(18). However, there are also transitions near 940, 1120, 1320, and $1440 \mathrm{~nm}$. Nd:YAG lasers operate in both pulsed and continuous mode. Pulsed Nd:YAG lasers are typically operated in the so called Q-switching mode: An optical switch is 
inserted in the laser cavity waiting for a maximum population inversion in the neodymium ions before it opens. Then the light wave can run through the cavity, depopulating the excited laser medium at maximum population inversion. In this Q-switched mode, output powers of 250 megawatts and pulse durations of 10 to 25 nanoseconds have been achieved(19). The high-intensity pulses may be efficiently frequency doubled to generate laser light at $532 \mathrm{~nm}$, or higher harmonics at 355 and $266 \mathrm{~nm}$. The high-intensity pulses may be efficiently frequency doubled to generate laser light at $532 \mathrm{~nm}$, or higher harmonics at 355 and $266 \mathrm{~nm}$.

Nd:YAG absorbs mostly in the bands between $730-760 \mathrm{~nm}$ and $790-820 \mathrm{~nm}(18)$. At low current densitieskryptonflash lamps have higher output in those bands than do the more common xenon lamps, which produce more light at around $900 \mathrm{~nm}$.

\section{Laser Parameters Determining The Success Of Laser Hair Reduction}

In general, three characteristics of the laser need to be taken intoaccount when considering hair destruction by photothermolysis:wavelength, flounce and pulse duration. The longer thewavelength, the deeper the laser light penetrates the skin. Theepidermis limits the amount of light that passes deeply into thedermis, reducing the effects of lasers on the germinate hair cells (20).

\begin{tabular}{|l|l|}
\hline \multicolumn{2}{|c|}{. Ruby Laser (694 Nm) } \\
\hline Wavelength & $694 \mathrm{Nm}$ \\
\hline Time Pulses & $25 \mathrm{~ns}$ \\
\hline Spot Size & $5 \mathrm{~mm}$ \\
\hline Influence & $20 \mathrm{To} 60 \mathrm{~J} / \mathrm{Cm}^{2}$ \\
\hline Repetition Rate & $3 \mathrm{~Hz}$ \\
\hline
\end{tabular}

\begin{tabular}{|l|l|}
\hline \multicolumn{2}{|c|}{ Alexandrite laser $\mathbf{( 7 5 5} \mathbf{~ n m})$} \\
\hline Wavelength & $755 \mathrm{~nm}$ \\
\hline Time pulses & $50 \mathrm{~ns}$ \\
\hline Spot Size & $3 \mathrm{~mm}$ \\
\hline Influence & $6-8 \mathrm{~J} / \mathrm{cm}^{2}$ \\
\hline Repetition Rate & $5 \mathrm{~Hz}$ \\
\hline
\end{tabular}

\begin{tabular}{|l|l|}
\hline \multicolumn{2}{|c|}{ Diode laser $(\mathbf{8 0 0} \mathbf{~ n m})$} \\
\hline Wavelength & $800 \mathrm{~nm}$ \\
\hline Time pulses & $5 \mathrm{~ns}$ \\
\hline Spot Size & $9 \mathrm{~mm}$ \\
\hline Influence & $10-40 \mathrm{~J} / \mathrm{cm}^{2}$ \\
\hline Repetition Rate & $1 \mathrm{~Hz}$ \\
\hline
\end{tabular}

\begin{tabular}{|l|l|}
\hline \multicolumn{2}{|c|}{.Nd:YAG laser $\mathbf{( 1 0 6 4} \mathbf{~ n m})$} \\
\hline Wavelength & $1064 \mathrm{~nm}$ \\
\hline Time pulses & $20 \mathrm{~ns}$ \\
\hline Spot Size & $3 \mathrm{~mm}$ \\
\hline Influence & $5-10 \mathrm{~J} / \mathrm{cm}^{2}$ \\
\hline Repetition Rate & $10 \mathrm{~Hz}$ \\
\hline
\end{tabular}

\section{Discussion:}

Laser-induced dermal adverse events depend on the properties of the laser light and laser-chromosphere interactions. Depending on the target chromospheres, the wavelengths of light will, in part, determine the depth of penetration and as such, the tissue interaction. In general, the penetration depth in skin increases with wavelength. For example, for hair removal, longer wavelength devices such as diode and Nd:YAG have lower absorption coefficients for melanin, thereby penetrating deeper into the epidermis/dermis where the hair bulb resides. By extending the time pulse of such lasers, the desired efficacy can be achieved, and the thermal-mediated adverse events reduce Figure (2). The comparison between different time pulses as shown in figure (3) show that laser Alexandrite have more time pulses but Nd-YAG laser with $20 \mathrm{~ns}$ is better in medicine . Figure (4) show that NdYAG laser with $3 \mathrm{~mm}$ of spot size is the in use for hair removal because it is very important in medicine is the good result of prevent hair growth again.

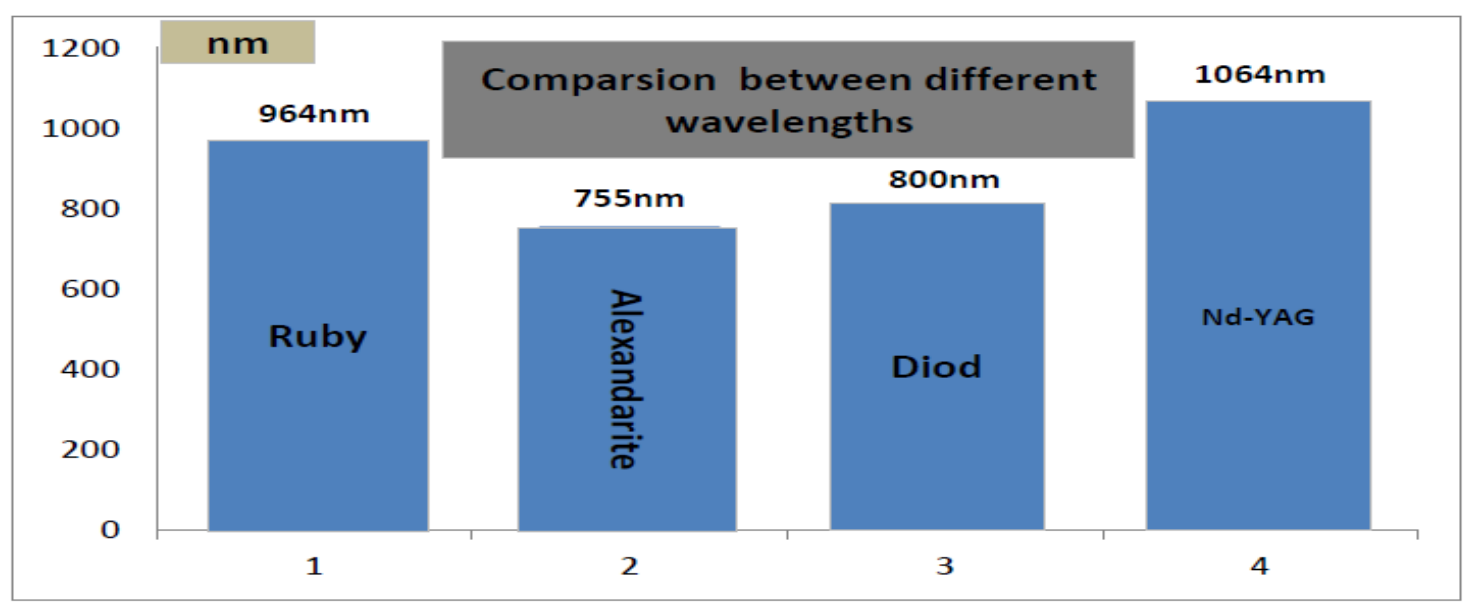

Figure (2) 


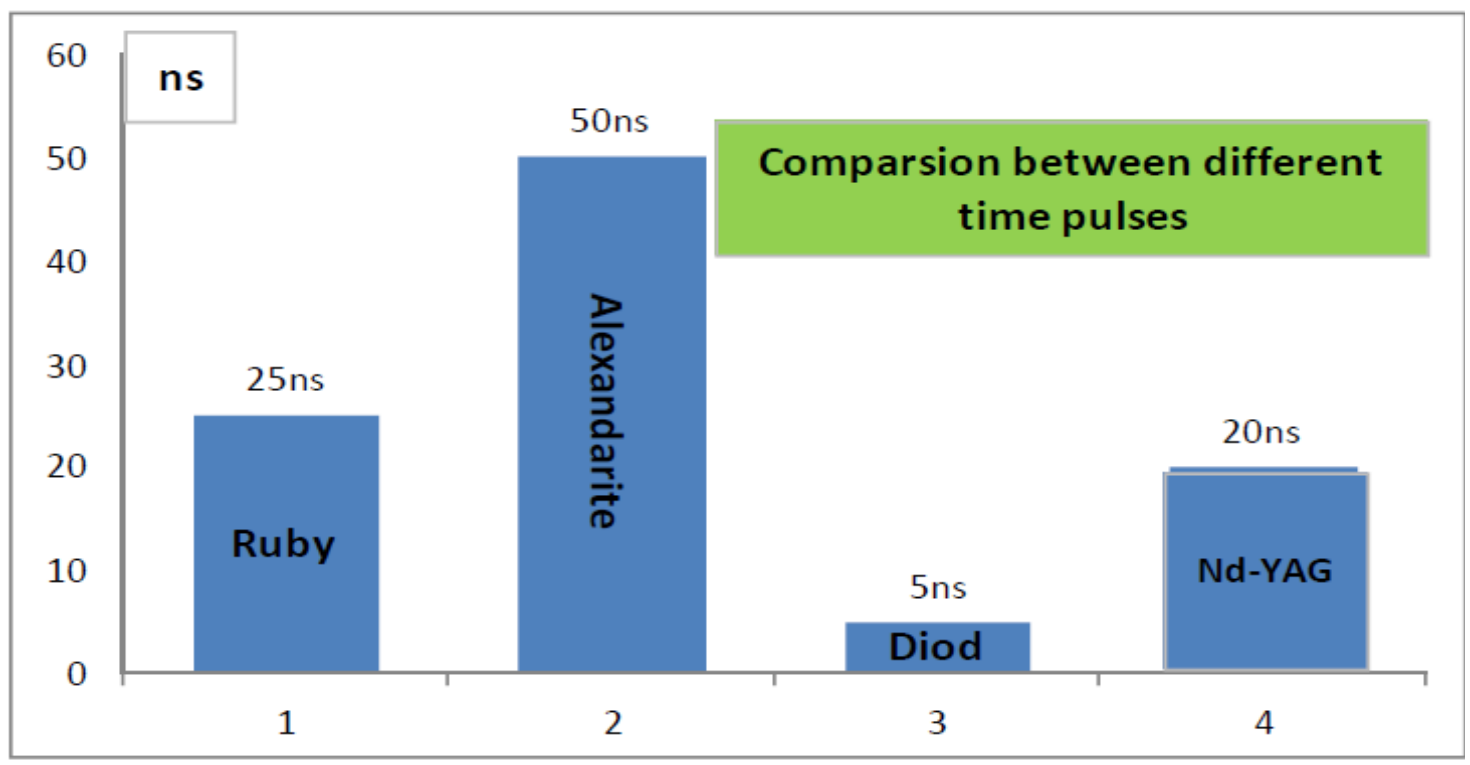

Figure (3)

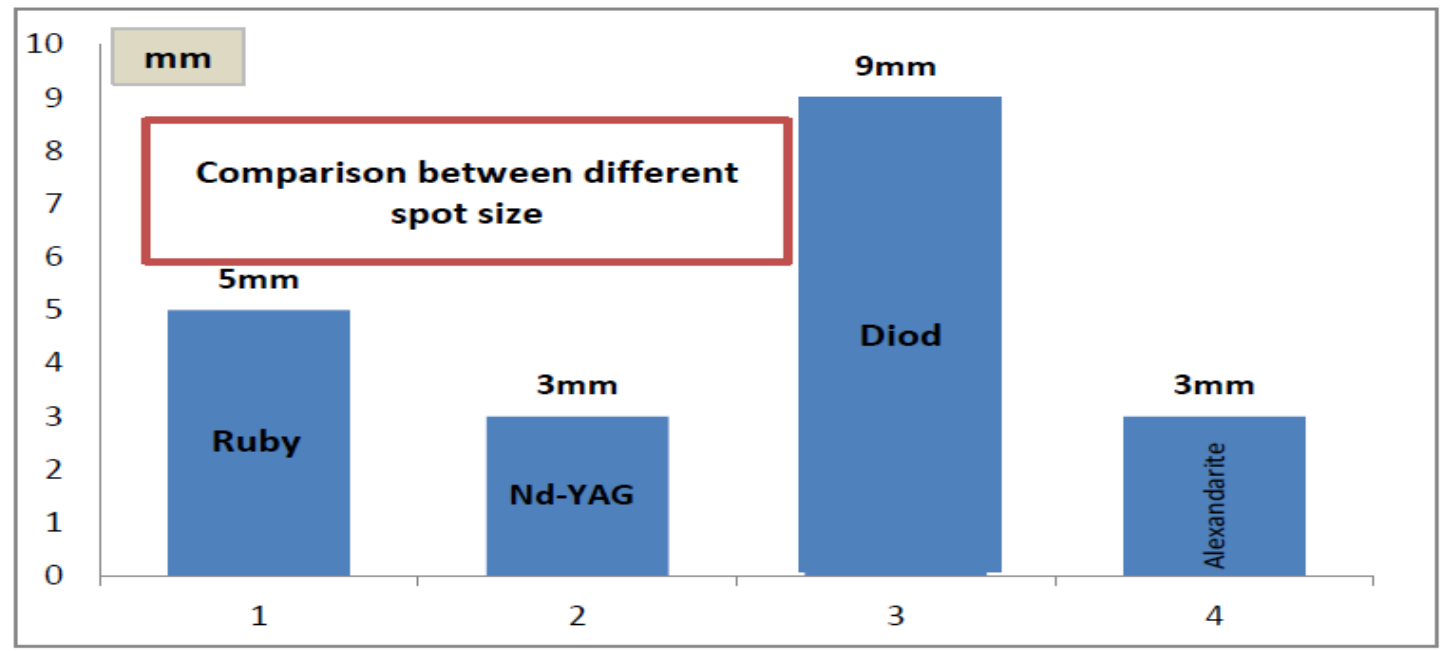

Figure (4)

\section{References}

[1]. Anderson RR, Parrish JA. photothermolysis: precise microsurgery by selectiveabsorption of pulsed radiation. Science. 1983 Apr 29; 220 (4596).

[2]. Goldberg DJ. Unwanted hair: evaluation and treatment with lasers and light source technology.

[3]. Adv Derm 1999; 14: 115-39.

[4]. Cotsarelis G, Sun TT, Lavker RM. Label-retaining cells reside in the bulge area of pilosebaceous unit: implications for follicular stem cells, hair cycle and skin carcinogenesis. Cell 1990;61: 1321-7.

[5]. Oliver RF. Whisker growth after removal of the dermal papilla and lengths of follicle in the hooded rat. J Embryol Exp Morphol 1966; 15: 331-47.

[6]. Olsen EA. Methods of hair removal. J Am Acad Dermatol 1999; 40: 143-55.

[7]. Dierckx CC, Grossman MC, Farinellii WA, et al. Permanent hair removal by normal mode ruby

[8]. laser. Arch Dermatol 1998; 134: 837-42.

[9]. Dierickx C, Campos VB, Lin WF, Anderson RR. Infl uence of hair growth cycle on efficacy of

[10]. $\quad$ laser hair removal. Lasers Surg Med 1999; 24(Suppl. 11): 21.8. G rossman MC, Dierickx CC, Farinelli W, et al. Damage to hair follicles by normal mode laser pulses. J Am Acad Dermatol 1996;889-94.

[11]. Anderson RR, Parrish JA. The optics of human skin. J Invest Dermatol 1981;77:13-19.

[12]. McDaniel DH, Lord J, Ask K, et al. Laser hair removal: a review and report on the use of the long pulsed alexandrite laser for hair reduction of the upper lip, leg, back, and bikini region. Dermatol Surg 1999;425-30.

[13]. Goldberg DJ, Ahkami R. Evaluation comparing multiple treatments with a 2 msec and 10 msec alexandrite laser for hair removal. Lasers Surg Med 1999;223-8.

[14]. $\quad$ Nanni CA, Alster TS. Long pulsed alexandrite laser assisted hair removal at 5, 10, and 20 millisecond pulse durations. Lasers Surg Med1999;332-7.

[15]. Dierickx CC, Grossman MC, Farinelli BS, et al. Hair removal by pulsed infrared diode laser.

[16]. Lasers Surg Med 1998;10(Suppl.). 
[17]. Dierickx CC, Grossman MC, Farinelli BS, et al. Comparison between a long pulsed ruby laser

[18]. $\quad$ and a pulsed, infrared laser system for hair removal. Lasers Surg Med 1998.

[19]. Grossman MC, Dierickx CC, Quintana A, et al. Comparison of various lasers for hair removal.

[20]. Lasers Surg Med 1998

[21]. Baumler W, Scherer K, Abels C, Neff S, Landthaler M, Szeimies RM. The effect of different

[22]. $\quad$ spot sizes on the efficacy of hair removal using a long-pulsed diode laser. Dermatol Surg 2002;

[23]. 28(2): 118-21.

[24]. Adrian RM, Shay KP. 800 nanometer diode laser hair removal in African American patients: A

[25]. clinical and histologic study. J Cutan Laser Ther 2000; 2(4): 183-90.

[26]. Yariv, Amnon (1989). Quantum Electronics (3rd ed.). Wiley. p. \$10.3, pp. 208-211.

[27]. Walter Koechner (1965) Solid-state laser engineering, Springer-Verlag, p. 507

[28]. Tong, A.K., Tan, O.T., Boll, J., Parrish, J.A. and Murphy, G.F. (1987) Ultra structure: effects of melanin pigment on target specificity using a pulsed dye laser (577 $\mathrm{nm}$ ). J. Invest. Demerol., 88, 747-752.

[29]. Fiskerstrand EJ, Svaasand LO, Nelson JS. Hair removal with long pulsed diode lasers: A comparisonbetween two systems with different pulse structures. Lasers Surg Med 2003; 32(5): 399-404. 